\title{
Medical management of inflammatory bowel disease among Canadian gastroenterologists
}

\author{
J Jones MD MSc FRCPC ${ }^{1}$, R Panaccione MD², ML Russell MD PhD ${ }^{3}$, R Hilsden MD PhD²,3
}

\begin{abstract}
J Jones, R Panaccione, ML Russell, R Hilsden. Medical management of inflammatory bowel disease among Canadian gastroenterologists. Can J Gastroenterol 2011;25(10):565-569.
\end{abstract}

BACKGROUND: Little is known about physician perceptions of and practices in using infliximab - a biological agent that was approved in Canada for the treatment of Crohn's disease in 2001, and for ulcerative colitis in 2006.

OBJECTIVES: To describe Canadian gastroenterologists' use and perceptions of infliximab in the treatment of refractory inflammatory bowel disease (IBD), and to identify factors that may influence a gastroenterologist's decision to initiate infliximab therapy.

METHODS: A postal questionnaire was distributed to all practicing clinicians captured in the 2007 membership of the Canadian Association of Gastroenterology. Each physician was contacted up to a maximum of three times.

RESULTS: Of 466 questionnaires mailed out, responses were received from $336(72 \%)$, with 292 respondents (63\%) returning fully completed surveys. For $80 \%$ of respondents, IBD patients comprised less than $30 \%$ of their clinical practice. Most prescribed infliximab at an initial dose of $5 \mathrm{mg} / \mathrm{kg}(97 \%)$, prescribed loading doses at 0, 2 and 6 weeks $(88 \%)$, premedicated with corticosteroids $(74 \%)$, administered maintenance infusions at eight-week intervals (89\%), co-administered immunosuppressive agents (81\%) and continued infliximab 'indefinitely' as long as it was effective and well tolerated (76\%). Most gastroenterologists $(>70 \%)$ identified lack of drug insurance coverage and provincial funding criteria as important barriers to prescribing infliximab.

CONCLUSIONS: Most Canadian gastroenterologists exhibited similar practice patterns with respect to the use of infliximab for induction and maintenance therapy of IBD. Common barriers to the initiation of infliximab therapy were identified.

\section{Key Words: Inflammatory bowel diseases; Infliximab; Treatment}

Tnflammatory bowel disease (IBD) is a chronic, incurable inflammatory disorder of the intestinal tract. It is believed to occur as a result of a complex interplay between an individual's genetics and their environment (1). Left untreated, IBD can lead to profound morbidity, with impaired health-related quality of life and time away from work $(2,3)$. Complications of the disease result in the need for prolonged hospitalizations and surgical intervention (4-6). Studies of resource use in IBD suggest that the economic burden associated with the direct costs of surgery and hospitalization is substantial $(7,8)$.

There have been rapid advancements in the understanding of disease pathogenesis and the development of therapeutic agents used to treat IBD during the past decade. Biological agents such as infliximab (a monoclonal antibody directed against tumour necrosis factor [TNF]alpha) have been demonstrated in randomized controlled trials (RCTs) to have the highest rates of clinical efficacy of any therapeutic agent to date $(9,10)$. However, infliximab is expensive and has been shown to be associated with some rare but potentially serious adverse events within

\author{
La prise en charge médicale des maladies \\ inflammatoires de l'intestin chez les \\ gastroentérologues canadiens
}

HISTORIQUE : On ne sait pas grand-chose des perceptions et des pratiques des médecins à l'égard de l'utilisation de l'infliximab, un agent biologique approuvé en 2001 au Canada pour traiter la maladie de Crohn, et en 2006 pour traiter la colite ulcéreuse.

OBJECTIFS : Décrire l'utilisation et les perceptions des gastroentérologues canadiens à l'égard de l'infliximab pour traiter les maladies inflammatoires de l'intestin (MII) réfractaires et déterminer les facteurs susceptibles d'influer sur la décision du gastroentérologue d'amorcer une thérapie à l'infliximab.

MÉTHODOLOGIE : Tous les cliniciens en exercice membres de l'Association canadienne de gastroentérologie en 2007 ont reçu un questionnaire par la poste. On a communiqué avec chaque médecin jusqu'à trois fois.

RÉSULTATS : Des 466 questionnaires postés, 336 (72\%) ont été retournés, et 292 (63\%) étaient entièrement remplis. Pour $80 \%$ des répondants, les patients atteints d'une MII représentaient moins de $30 \%$ de leur pratique clinique. La plupart prescrivaient de l'infliximabà une dose initiale de $5 \mathrm{mg} / \mathrm{kg}(97 \%)$, prescrivaient des doses d'attaque à zéro, deux et six semaines ( $88 \%$ ), prescrivaient une prémédication aux corticoïdes (74\%), administraient des infusions d'entretien toutes les huit semaines (89\%), coadministraient des immunosuppresseurs (81\%) et maintenaient l'infliximab « indéfiniment », tant qu'il était efficace et bien toléré (76\%). La plupart des gastroentérologues (plus de $70 \%$ ) précisaient que l'absence de protection d'assurance et que les critères de financement provinciaux constituaient d'importants obstacles à la prescription d'infliximab.

CONCLUSIONS : La plupart des gastroentérologues canadiens adoptaient des modes de pratique similaires pour ce qui est de l'utilisation de l'infliximab comme thérapie d'induction et d'entretien de la MII. Les obstacles courants à l'amorce de la thérapie ont été énumérés.

the context of clinical trials, postmarketing surveillance programs and treatment registries. Clinical and pharmacokinetic studies have reported the optimal dose range and interval regimen for the administration of infliximab (9-11). Deviation from these clinical protocols has been shown to be associated with increased rates of infusion reactions and loss of response to the medication due, in part, to the development of immunogenicity. This has prompted the publication of consensus guidelines by many IBD organizations in several different countries (12).

Little research determining how clinicians use biological agents in real-world clinical practice has been performed. Similarly, the medical literature has very little information about the factors that influence patterns of infliximab use among gastroenterologists who treat patients with IBD. This information is essential to facilitate a better understanding of the continuing medical education (CME) needs of the gastroenterology community. Such information can also assist policy makers in regional and national health care planning and resource distribution. In Canada, medication costs are not covered under the

${ }^{1}$ Departments of Medicine and Community Health and Epidemiology, University of Saskatchewan, Saskatoon, Saskatchewan; ${ }^{2}$ Department of Medicine;

${ }^{3}$ Department of Community Health Sciences, University of Calgary, Calgary, Alberta

Correspondence: Dr J Jones, Department of Medicine, Royal University Hospital, 103 Hospital Drive, Saskatoon, Saskatchewan S7N OW8.

Telephone 306-966-7985, fax 306-966-7996, e-mail j.jones@usask.ca

Received for publication February 23, 2011. Accepted May 16, 2011 


\section{TABLE 1}

\section{Scenarios on which questions were based*}

Scenario 1 You see a 36-year-old man with severe, steroid refractory Crohn's ileocolitis who has been treated with azathioprine for 5 months at a dose of $150 \mathrm{mg}$ orally daily (patient weighs $70 \mathrm{~kg}$ ). After a thorough evaluation and consideration of all options, you have decided to prescribe infliximab

Scenario 2 You are seeing a 25-year-old man with newly diagnosed, colonic Crohn's disease of moderate severity. He was recently started on prednisone with good clinical response. This patient has asked you about initiating infliximab

Scenario 3 You see a 31-year-old man with a 3-year history of ileocolonic Crohn's disease. He underwent a limited terminal ileal resection 1 year ago. He now has clinical, endoscopic and radiographic evidence of recurrent neoterminal ileal disease (inflammatory), which has been unresponsive to azathioprine and methotrexate

Scenario $4 \quad$ You are following a 35-year-old man with a 5-year history of ileal Crohn's disease. He has required 3 extensive ileal resections (80 $\mathrm{cm}$ each) for stricturing complications. He presents with clinical, radiographic and endoscopic evidence of disease recurrence despite ongoing therapy with azathioprine $(2.5 \mathrm{mg} / \mathrm{kg})$ for 1 year

*The full, unabridged questionnaire can be viewed at www.pulsus.com

universal health care system. Patients often carry private, personal insurance to cover the costs of their medications. Each province exercises its own discretion in deciding whether to subsidize the cost of a medication. Costly medications, such as infliximab, are considered special medications and patients must fulfill a specific set of criteria (ie, exceptional health status) to be considered for medication coverage by each province.

The objectives of the present study were to describe the clinical patterns of infliximab use for the treatment of medically refractory IBD by Canadian physicians involved in the medical treatment of patients with IBD, and to determine whether practice- or physician-related factors, demographic factors, method of $\mathrm{CME}$ or region of practice influence patterns of infliximab use.

\section{METHODS}

\section{Target population and sampling frame}

A postal questionnaire was mailed to the 466 clinician members of the Canadian Association of Gastroenterology (CAG) in 2007. The membership of this organization is national and likely captures $90 \%$ of the practicing Canadian gastroenterologists involved in the medical management of IBD. This was determined by comparing the number of clinician members of the CAG with the total number of Canadian clinicians meeting a recently proposed administrative definition of a gastroenterologist as per Moayyedi et al (13) in 2007.

\section{Questionnaire development}

A postal questionnaire was developed and administered according to the principles of Choi and Pak (14) to minimize bias, as well as the tailored design principles of Dillman (15). The questions were scenario based and closed ended (Table 1). Questions were designed to evaluate clinical patterns of infliximab use in the treatment of medically refractory IBD, as well as drug-related and nonpharmacological factors that might influence the decision to prescribe infliximab. Specific practice patterns of interest pertained to the following: whether physicians use infliximab; the dose of infliximab used; how often and at what interval infliximab is given; whether physicians administer other immunosuppressants (IS) with infliximab; whether physicians use corticosteroids as premedication with infliximab; how

\begin{tabular}{|l|c|c|c|c|c|}
\hline & \multicolumn{5}{|c|}{ Time } \\
\cline { 2 - 6 } & -4 days & Week 0 & Week 3 & Week 6 & Week 9 \\
\hline Phase 1. Pre-notice letter & $\mathrm{X}$ & & & & \\
\hline Phase 2. First survey with incentive & & $\mathrm{X}$ & & & \\
\hline $\begin{array}{l}\text { Phase 3. Thank you replacement } \\
\text { questionnaire \& non-responder card }\end{array}$ & & & $\mathrm{X}$ & & \\
\hline $\begin{array}{l}\text { Phase 4. Second replacement } \\
\text { questionnaire \& non-responder card }\end{array}$ & & & & $\mathrm{X}$ & \\
\hline Study completion & & & & & $\mathrm{X}$ \\
\hline
\end{tabular}

Figure 1) Flow sheet outlining survey implementation

long physicians treat patients with infliximab; and what physicians do when patients lose response to infliximab. The practice- and physicianrelated factors evaluated included the following: proportion of IBD patients in clinical practice; type of practice (academic versus community); years in practice; and province in which the physician practiced. In addition, specific inquiry regarding the impact of specific barriers to infliximab use was made.

Pilot testing was undertaken among a small group of eight local gastroenterologists including community-based $(n=2)$ and academic gastroenterologists $(n=3)$, as well as gastroenterology trainees $(n=3)$. Pilot testing was performed by distributing the questionnaire to these individuals. These individuals were then met with separately to discuss identified design flaws, and to ensure comprehensibility and appropriateness of content and format. The motivational quality (level of interest to the respondent) of the questionnaire was also evaluated to increase the likelihood of survey completion and to minimize item nonresponse. Five of these gastroenterologists were subsequently involved in the main survey.

\section{Questionnaire distribution}

Standard letter mail was used to contact the participants. Several evidence-based techniques proven to maximize response rates to mail surveys were used $(14,15)$. Survey distribution consisted of four mailouts (Figure 1). A brief prenotification letter preceded the first questionnaire by four days. A nonconditional incentive in the form of a gift certificate valued at $\$ 15$ from a national bookstore chain was included with the initial questionnaire. Final analysis was performed using data from questionnaires received within three months of the final questionnaire mailout. Individuals who did not wish to complete the questionnaire or who were not eligible to do so were asked to return an abbreviated 'refuser/not eligible' questionnaire that posed the following seven questions:

1. Have you previously used, do you currently use or do you intend to use infliximab as part of the medical management of IBD patients? 2. To what age group do you belong?

3. How many years have you been in clinical practice?

4. Which of the following best describes your practice (academic versus community)?

5. What proportion of your time is allocated to clinical duties?

6. What percentage of your practice is comprised of patients with IBD?

7. How many times have you prescribed infliximab within the past six months?

Due to privacy laws, the 2007 CAG membership list was not made available to the investigators; instead, all responses were tracked by the CAG administration. The study codes, not the personal identity, corresponding to the nonrespondents were then revealed to the investigators. At no time was the CAG administration aware of an individual's response because the envelopes in which the questionnaires were returned were never opened by the CAG. The present study was approved by the Conjoint Health Research Ethics Board of the University of Calgary (Calgary, Alberta) on May 15, 2007. 
TABLE 2

\section{Summary of response rates}

\begin{tabular}{lccc}
\hline & \multicolumn{3}{c}{ Questionnaires } \\
\cline { 2 - 4 } Respondent type & $\begin{array}{c}\text { Eligible, } \\
\mathbf{n}\end{array}$ & $\begin{array}{c}\text { Returned or } \\
\text { completed, } \mathbf{n}\end{array}$ & $\begin{array}{c}\text { Returned, } \\
\%\end{array}$ \\
\hline $\begin{array}{l}\text { Overall } \\
\text { Responders returning } \\
\quad \text { completed questionnaires }\end{array}$ & $336^{\star}$ & 336 & 72 \\
$\quad$ & $292^{\ddagger}$ & 87 \\
$\quad$ Those who chose to return & $336^{\dagger}$ & 44 & 13 \\
$\quad$ nonresponse forms & & & \\
Fully completed questionnaires & $292^{\ddagger}$ & 287 & 98 \\
Early responders & $336^{\dagger}$ & 190 & 57 \\
Intermediate responders & $336^{\dagger}$ & 76 & 23 \\
Late responders & $336^{\dagger}$ & 68 & 20 \\
\hline
\end{tabular}

*Includes responders and those choosing to return a nonresponder form;

†Only those returning questionnaires; ${ }^{\ddagger}$ Responders returning completed questionnaires

\section{Statistical analysis}

Final analysis was performed using data from questionnaires received within three months of the final questionnaire mailing. Responders were classified as 'early' or 'late' to determine whether there were systematic differences between the characteristics of early versus late respondents (assuming the late respondents were similar in nature to nonrespondents) to assess nonresponse bias.

A precision-based estimate of sample size was calculated, with 210 completed respondent questionnaires required to provide an acceptable sampling error (approximately 5\%) and a 95\% CI for the obtained point estimate(s) (15). Thus, a response rate of $45 \%$ was required to ensure precision of the survey responses. All data analysis was descriptive. Response rates were calculated by dividing the number of respondents by the total number of participants to whom the survey was distributed (a denominator of 466). Group comparisons of the proportion of responses to each questionnaire item were performed using $\chi^{2}$ analysis or Fisher's exact test. Means, SDs and ranges of responses were presented, with 95\% CIs constructed for all point estimates. The alpha for statistical testing was set at $5 \%$ for each questionnaire item. All data analysis was performed using Stata SE version 9.0 (Stata Corporation, USA).

\section{Response rate}

\section{RESULTS}

The overall response rate (including completed questionnaires and those returning nonresponse forms) was 72\% (336 of 466) (Table 2). Sixty-three per cent returned completed questionnaires (292 of 466). More than two-thirds were early responders (those returning a completed questionnaire within two weeks of the second mailing). A total of $9.4 \%$ (44 of 466) returned 'refuser/not eligible' questionnaires and were deemed ineligible for the survey. Thus, the response rate among those eligible for the survey was $79.6 \%$ (336 of 422). Item response was very high (98\% [287 of 292]).

\section{Respondent characteristics}

The demographic characteristics of the respondents are summarized in Table 3. More than two-thirds of respondents were older than 44 years of age, and almost $70 \%$ had been in clinical practice for more than a decade (Table 3). Fifty-three per cent self-reported having an academic practice, and the majority of respondents' practices consisted of more than $50 \%$ clinical practice. Only $10 \%$ of respondents described a clinical caseload of more than 50\% IBD.

\section{Patterns of infliximab use}

The vast majority of respondents identified medically refractory IBD, fistulizing Crohn's disease (CD) and steroid-dependent CD as indications for infliximab use (Table 4). Fewer gastroenterologists recognized pyoderma gangrenosum, ankylosing spondylitis or new, severely
TABLE 3

Respondent demographics

\begin{tabular}{lc}
\hline Demographic and practice-related factors & $\mathbf{n}(\%)$ \\
\hline Age group, years & $9(3)$ \\
$<30$ & $124(37)$ \\
$30-44$ & $147(44)$ \\
$45-59$ & $51(15)$ \\
$60-74$ & $1(0.30)$ \\
$\geq 75$ & \\
Years in clinical practice & $63(19)$ \\
$<5$ & $40(12)$ \\
$5-9$ & $106(32)$ \\
$10-19$ & $84(25)$ \\
$20-30$ & $39(12)$ \\
$>30$ & \\
Practice description & $177(53)$ \\
Academic & $155(47)$ \\
Community & \\
Percentage of time in clinical activities & $41(20)$ \\
$\leq 30$ & $34(16)$ \\
$31-50$ & $51(24)$ \\
$51-74$ & $84(40)$ \\
$75-100$ & \\
Percentage of patients with IBD & $192(58)$ \\
$\leq 30$ & $105(32)$ \\
$31-50$ & $27(8)$ \\
$51-74$ & $8(2)$ \\
$75-100$ &
\end{tabular}

IBD Inflammatory bowel disease

active $\mathrm{CD}$ as an indication for infliximab use (Table 4). There was consistency in the regimens for using infliximab: $97 \%$ started with a dose of $5 \mathrm{mg} / \mathrm{kg}$; $88 \%$ used a three-dose induction regimen; and $89 \%$ provided maintenance infusions at eight-week intervals (Table 5). Three-quarters $(75 \%)$ used steroids as premedication before infliximab infusions, $80 \%$ co-administered IS with infliximab, $77 \%$ indicated that they would continue infliximab indefinitely provided that it was effective and well tolerated, and $76 \%$ indicated that they would decrease the infliximab interval if a patient exhibited loss of response to the drug, presumably as a result of immunogenicity.

Influence of practitioner- and practice-related factors on patterns of infliximab use

Physicians with academic practices differed from those with primarily community practices with respect to the concomitant administration of IS and the strategy used on loss of response to infliximab. Of the respondents who indicated that they did not co-administer IS with infliximab, $72 \%$ (32 of 47 ) were in academic practice compared with $13 \%$ (28 of 47$)$ in community practice $(\mathrm{P}<0.01)$. Respondents in academic practice were more likely to continue infliximab for one year (as opposed to three months, six months or indefinitely) as long as the drug was well tolerated and effective, compared with respondents in community practice $(67 \%$ versus $33 \%[\mathrm{P}<0.05])$. Physician age, number of years in clinical practice, proportion of case mix consisting of IBD and proportion of clinical work performed were not associated with differences in how respondents used infliximab.

Influence of practice region on patterns of infliximab use

Response distributions were stratified according to the region in which a clinician practiced: western Canada, Ontario, Quebec or Atlantic Canada. A larger proportion of clinicians in western Canada administered infliximab induction doses as a single infusion or as two infusions at weeks 0 and 4 . Practice region was not associated with any other aspect of practice pattern. 


\section{TABLE 4}

Patterns of infliximab use among responders*

\begin{tabular}{|c|c|c|}
\hline & n (\%) & 95\% Cl (Binomial Wald) \\
\hline \multicolumn{3}{|l|}{ Steroid premedication } \\
\hline Yes & $219(75)$ & $0.70-0.80$ \\
\hline No & $72(24)$ & $0.20-0.30$ \\
\hline \multicolumn{3}{|c|}{ Infliximab dose, $\mathrm{mg} / \mathrm{kg}$} \\
\hline 5 & $281(97)$ & $0.95-0.99$ \\
\hline 7.5 & $3(1)$ & $0.002-0.03$ \\
\hline 10 & $3(1)$ & $0.002-0.03$ \\
\hline \multicolumn{3}{|l|}{ Induction therapy } \\
\hline Single dose & $18(6)$ & $0.03-0.09$ \\
\hline 0 and 4 weeks & $8(3)$ & $0.009-0.05$ \\
\hline 0,2 and 6 weeks & $257(88)$ & $0.85-0.92$ \\
\hline \multicolumn{3}{|l|}{ Maintenance therapy } \\
\hline 6-week interval & $5(2)$ & $0.002-0.03$ \\
\hline 8-week interval & $260(89)$ & $0.86-0.93$ \\
\hline 10-week interval & $2(0.7)$ & $0.001-0.02$ \\
\hline 12-week interval & $2(0.7)$ & $0.001-0.02$ \\
\hline On demand & $15(5)$ & $0.03-0.77$ \\
\hline \multicolumn{3}{|c|}{ Immunosuppressant co-administration } \\
\hline Yes & $232(80)$ & $0.75-0.84$ \\
\hline No & $47(16)$ & $0.12-0.20$ \\
\hline \multicolumn{3}{|l|}{ Infliximab duration } \\
\hline 3 months & $3(1)$ & $0.002-0.03$ \\
\hline 6 months & $4(1)$ & $0.004-0.04$ \\
\hline 1 year & $36(12)$ & $0.09-0.16$ \\
\hline Indefinitely & $223(77)$ & $0.004-0.82$ \\
\hline \multicolumn{3}{|c|}{ Infliximab use on loss of response } \\
\hline Decrease interval & $222(76)$ & $0.71-0.81$ \\
\hline Increase dose & $51(18)$ & $0.13-0.22$ \\
\hline Stop infliximab & $2(0.7)$ & $0.001-0.03$ \\
\hline
\end{tabular}

*In cells in which the responses do not add to $100 \%$, the remainder of responses consisted of either "other" or "I don't know"

\section{Barriers to infliximab use}

All of the following factors were considered to represent major barriers to the prescribing of infliximab by the majority of respondents: drug cost, personal insurance coverage, provincial funding criteria, the absence of infusion facilities and lack of trained personnel to administer infliximab. More than $50 \%$ of respondents identified drug cost as being an important factor to consider when deciding to initiate infliximab infusions $(0.52$ [ $95 \%$ CI 0.46 to 0.57$]$ ). More than $90 \%$ of respondents believed that drug insurance coverage for individual patients was an important factor to consider when deciding to initiate infliximab therapy. Seventy-one per cent of respondents considered provincial funding criteria to be either important or extremely important when deciding whether to initiate infliximab infusions (0.71 [95\% CI 0.65 to 0.76$]$ ). More than $50 \%$ of respondents believed that both the absence of infusion facilities and the absence of trained personnel were important factors to consider when deciding whether to initiate infliximab infusions.

\section{Influence of CME on patterns of infliximab use}

The majority of respondents indicated that they participated in CME activities in one or more of the following formats: large groups; expert seminars; review of clinical guidelines; review of medical text books or journals; and consultation with peers. Only 27\% indicated that they participated in apprenticeships (clinical observation of an 'expert' clinician or opinion leader in the field). Stratification according to CME activity (defined as respondents who indicated that they 'often' participate in a CME activity) revealed that only apprenticeship seemed to alter the response distribution of specific questionnaire items. Premedication with corticosteroids and the co-administration of IS were both significantly impacted by apprenticeship.
TABLE 5

Summary of infliximab indication identified by respondents

\begin{tabular}{lcc}
\hline & $\mathbf{n ~ ( \% )}$ & 95\% Cl (Binomial Wald) \\
\hline Medically refractory UC & $264(91)$ & $0.874-0.941$ \\
Medically refractory CD & $291(100)$ & - \\
Fistulizing CD & $285(98)$ & $0.963-0.996$ \\
Pyoderma gangrenosum & $196(67)$ & $0.619-0.728$ \\
Ankylosing spondylitis & $168(58)$ & $0.521-0.634$ \\
New, severe CD & $66(23)$ & $0.178-0.275$ \\
Steroid-dependent CD & $249(86)$ & $0.815-0.896$ \\
\hline
\end{tabular}

CD Crohn's disease; UC Ulcerative colitis

\section{DISCUSSION}

The current comprehensive study was the first specifically designed to evaluate the patterns of infliximab use among gastroenterologists. The responses to the survey items suggested that the vast majority of gastroenterologists use infliximab in a similar fashion. High-quality data exist to justify the practice patterns inferred from questionnaire items that elicited the greatest level of participant agreement. However, there was variability in the distribution of responses to selected questionnaire items. One-quarter of respondents were not in agreement with respect to the co-administration of IS therapy. This is meaningful, and likely reflective of the concerns and controversies that currently exist in the scientific community. Recent research has revealed the importance of engaging in medical practices that maximize the duration of effectiveness of the initial anti-TNF biological agent to which an individual is exposed (16-21). Data from post hoc subgroup analyses derived from clinical trials, observational studies and, more recently, the results of two large RCTs designed to address this issue $(9,10,20,21)$ have led to confusion and uncertainty with respect to best practice in this area. Despite this, the vast majority of respondents indicated that they would co-administer IS agents with infliximab. This may be reflective, in part, of the influence of Canadian opinion leaders in the field of IBD who have delivered a high volume of CME activities over the past several years. This fact may also explain why respondent participation in apprenticeship CME activities appeared to influence practice patterns. In addition, the past publication of Canadian consensus guidelines pertaining to infliximab use advocated the concomitant use of IS therapy and may have influenced Canadian IBD practice (12). The uncertain additive benefit of concomitant IS therapy in select patient populations above and beyond scheduled infliximab infusions has also led gastroenterologists to question the additive benefit of corticosteroid premedication. This fact also appears to be reflected in the distribution of responses to questions about the use of corticosteroids as premedication to infliximab. A similar questionnaire designed to evaluate American gastroenterologists' patterns of infliximab use was distributed during a similar time frame. That survey was distributed to gastroenterologists practicing in Maryland and Washington, DC (USA) (22), with only $28.6 \%$ of gastroenterologists responding (96 of 336). The authors inferred that the respondents underused immunomodulators, failed to use maintenance infliximab and had a lack of awareness of major infliximab-related adverse events. However, due to the low response rate, caution must be exercised when interpreting the results of that study given the potential for nonresponse bias.

The responses to questions pertaining to strategy on loss of response in primary infliximab responders were not uniform. In general, immunogenical loss of response can be addressed by increasing infliximab dose to 'overwhelm' antibody response, or to decrease infliximab interval to intervene with the next infusion before the trough serum infliximab concentration decreases below known therapeutic levels (17). In the absence of any high-quality data to support the superiority of one strategy over the other, clinicians have been left to their own devices to deal with such problems. The fact that the majority of respondents indicated that they would decrease the infliximab interval upon loss of response might be reflective of the sense of fiscal responsibility felt by physicians working within the Canadian 
health care system. Purely from the perspective of pharmaceutical cost, doubling the dose of infliximab would be more expensive than decreasing the infusion interval from eight weeks to six weeks. Most patients who require infliximab in Canada must fulfill a set of criteria for the provincial government to subsidize the cost of the medication (ie, exceptional drug status). Thus, increasing the drug dose significantly increases the cost burden to both the government and the patient. In provinces in which infliximab infusions are provided through private infliximab infusion facilities (now in most provinces in Canada), the direct nonpharmaceutical medical costs associated with infliximab infusions are absorbed by private industry. Although Canadian gastroenterologists may try to decrease the financial burden placed on patients who cannot afford to cover the residual cost of escalating infliximab doses, increasing the frequency of infliximab infusions increases the indirect and societal costs through increased time away from work, lost wages and decreased productivity.

The observed differences in the responses to questions pertaining to concomitant IS use, corticosteroid premedication and duration of infliximab therapy among physicians in academic practice versus community-based practice could be explained in several ways. Gastroenterologists in academic practice likely work in close proximity to opinion leaders in the field of IBD and attend IBD educational rounds more frequently. Thus, they may have increased exposure to discussion and debate relating to the utility of steroid premedication and concomitant IS therapy. Similarly, concerns related to the potential long-term effects of prolonged anti-TNF use may be communicated in a more timely manner to gastroenterologists working at academic centres, who have the benefit of listening to visiting experts. The observed influence of 'practice region' on infliximab initiation regimen and on the perceived barriers to infliximab use may be a result of more stringent provincial funding criteria in these regions at the time the survey was conducted.

The results of the present survey suggest that Canadian gastroenterologists practice similarly with respect to the use of infliximab in the management of patients with medically refractory Crohn's disease.

\section{REFERENCES}

1. Sartor RB. Therapeutic manipulation of the enteric microflora in inflammatory bowel diseases: Antibiotics, probiotics, and prebiotics. Gastroenterology 2004;126:1620-33.

2. Feagan BG, Fedorak RN, Irvine EJ, et al. A comparison of methotrexate with placebo for the maintenance of remission in Crohn's disease. North American Crohn's Study Group Investigators. N Engl J Med 2000;342:1627-32.

3. Feagan BG. Review article: Economic issues in Crohn's disease assessing the effects of new treatments on health-related quality of life. Aliment Pharmacol Ther 1999;13(Suppl 4):29-37; discussion 8.

4. Farmer RG, Easley KA, Rankin GB. Clinical patterns, natural history, and progression of ulcerative colitis. A long-term follow-up of 1116 patients. Dig Dis Sci 1993;38:1137-46.

5. Farmer RG, Hawk WA, Turnbull RB Jr. Clinical patterns in Crohn's disease: A statistical study of 615 cases. Gastroenterology 1975;68:627-35.

6. Munkholm P. Crohn's disease - occurrence, course and prognosis. An epidemiologic cohort study. Dan Med Bull 1997;44:287-302.

7. Feagan BG, Vreeland MG, Larson LR, Bala MV. Annual cost of care for Crohn's disease: A payor perspective. Am J Gastroenterol 2000;95:1955-60.

8. Bernstein CN, Papineau N, Zajaczkowski J, Rawsthorne P, Okrusko G, Blanchard JF. Direct hospital costs for patients with inflammatory bowel disease in a Canadian tertiary care university hospital. Am J Gastroenterol 2000;95:677-83.

9. Sands BE, Anderson FH, Bernstein CN, et al. Infliximab maintenance therapy for fistulizing Crohn's disease. N Engl J Med 2004;350:876-85.

10. Hanauer SB, Feagan BG, Lichtenstein GR, et al. Maintenance infliximab for Crohn's disease: The ACCENT I randomised trial. Lancet 2002;359:1541-9.

11. Rutgeerts P, Diamond RH, Bala M, et al. Scheduled maintenance treatment with infliximab is superior to episodic treatment for the
Contradiction and uncertainty in the medical literature appears to be mirrored in the clinical practice of gastroenterologists when it comes to particular aspects of managing medically refractory Crohn's disease with infliximab. The results of the present study will assist gastrointestinal educational governing bodies in the development of specific and targeted educational programs, and underscore the need for high-quality RCTs that serve to further define best strategies in the use of biologicals for the treatment of patients with IBD. These results will also help the Canadian clinical research community identify relevant topics pertaining to the medical management of IBD for future research.

\section{STUDY HIGHLIGHTS}

- Strategic use of biologicals was quite similar among gastroenterologists with the exception of the following:

- Concomitant use of immunosuppression

- Strategy upon loss of response

- Key practice-related and demographic factors influence IBD practice patterns

\section{WHAT IS NEW HERE?}

- Confusion exists among practicing gastroenterologists with respect to the following:

- The appropriateness of concomitant immunosuppressive therapy with infliximab

- The most appropriate action upon loss of response to infliximab

CONFLICTS OF INTEREST: Drs Jones and Panaccione have served on advisory boards and acted as consultants to Schering-Plough Canada. There are no conflicts of interest to declare for Drs Russell and Hilsden.

CONTRIBUTIONS: Dr Jones was responsible for the concept, method development, study conduct, data analysis and manuscript development. Drs Hilsden, Russell and Panaccione provided methodological support and assisted with the development of the manuscript.

healing of mucosal ulceration associated with Crohn's disease. Gastrointest Endosc 2006;63:433-42.

12. Panaccione R, Fedorak RN, Aumais G, et al. Canadian Association of Gastroenterology clinical practice guidelines: The use of infliximab in Crohn's disease. Can J Gastroenterol 2004;18:503-8.

13. Moayyedi P, Tepper J, Hilsden R, Rabaneck L. International comparisons of manpower in gastroenterology. Am J Gastroenterol 2007;102:478.

14. Choi BCK, Pak AWP. A catalogue of biases in questionnaires. Prev Chronic Dis 2005;2:1-13.

15. Dillman DA. Mail and Internet Survey, The Tailored Design Method, 2nd edn. New York: John Whiley and Sons Inc, 2000.

16. Sandborn WJ, Rutgeerts P, Enns R, et al. Adalimumab induction therapy for Crohn disease previously treated with infliximab: A randomized trial. Ann Intern Med 2007;146:829-38.

17. Rutgeerts P, Van Assche G, Vermeire S. Optimizing anti-TNF treatment in inflammatory bowel disease. Gastroenterology 2004;126:1593-610.

18. Rutgeerts P, Feagan BG, Lichtenstein GR, et al. Comparison of scheduled and episodic treatment strategies of infliximab in Crohn's disease. Gastroenterology 2004;126:402-13.

19. Maser EA, Villela R, Silverberg MS, Greenberg GR. Association of trough serum infliximab to clinical outcome after scheduled maintenance treatment for Crohn's disease. Clin Gastroenterol Hepatol 2006;4:1248-54

20. Feagan BG, Panaccione R, Enns R, et al. A randomized trial of methotrexate in combination with infliximab for the treatment of Crohn's disease. Gastroenterology 2008;135:294-5.

21. Columbel SF, Sandborn WJ, Reinisch W, et al. Infliximab, azathiprine or combination therapy for Crohn's disease. N Engl J Med 2010;362:1383-95.

22. Donovan M, Lunney K, Carter-Pokras O, Cross RK. Prescribing patterns and awareness of adverse effects of infliximab: A health survey of gastroenterologists. Dig Dis Sci 2007;52:1798-805. 


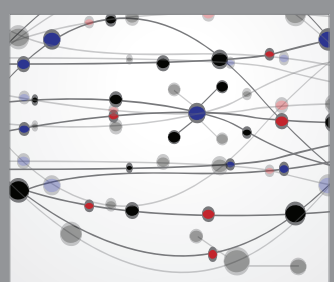

The Scientific World Journal
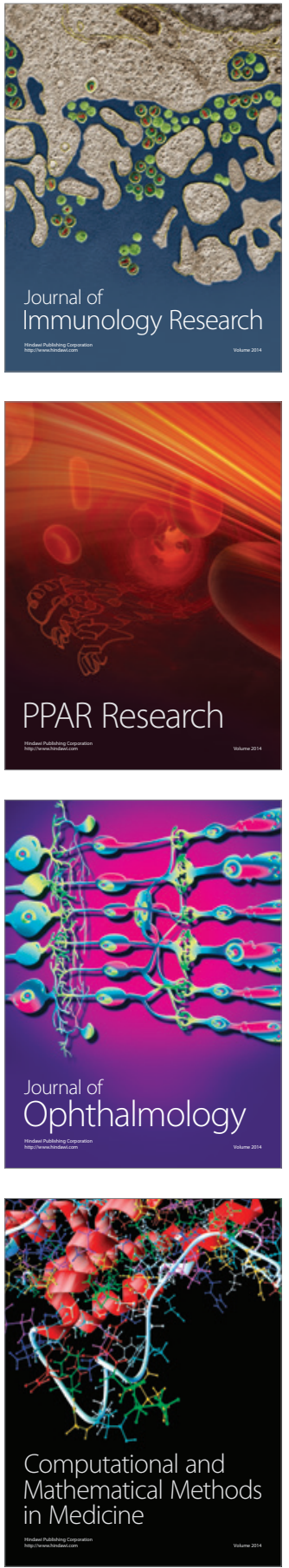

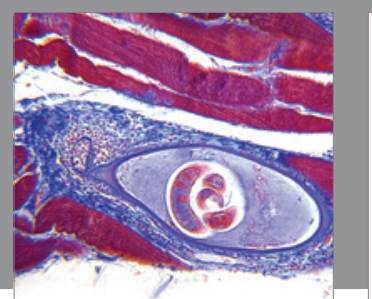

Gastroenterology Research and Practice

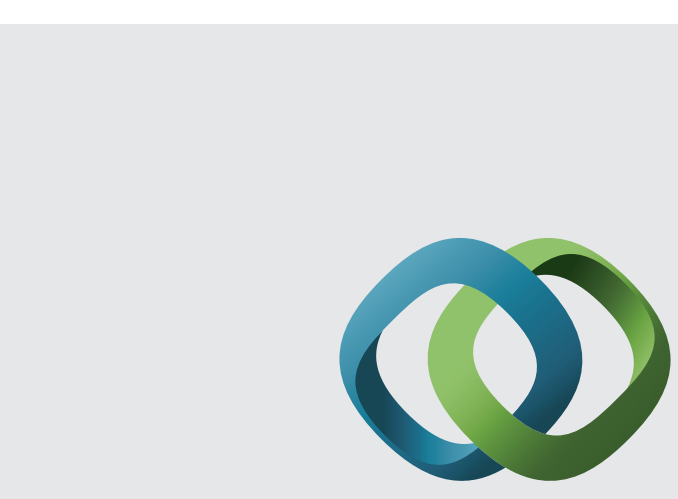

\section{Hindawi}

Submit your manuscripts at

http://www.hindawi.com
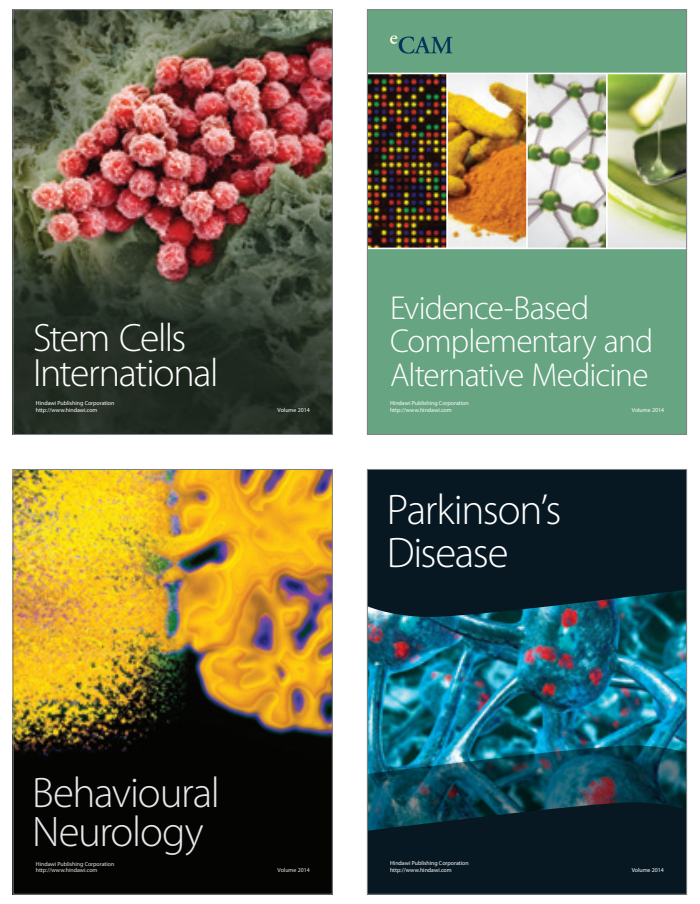
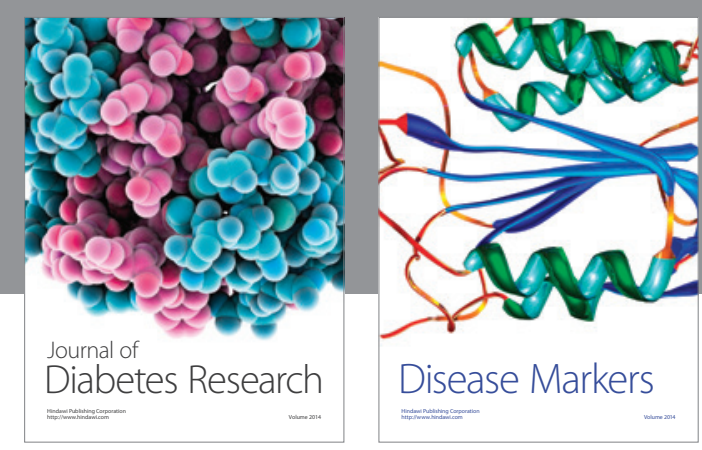

Disease Markers
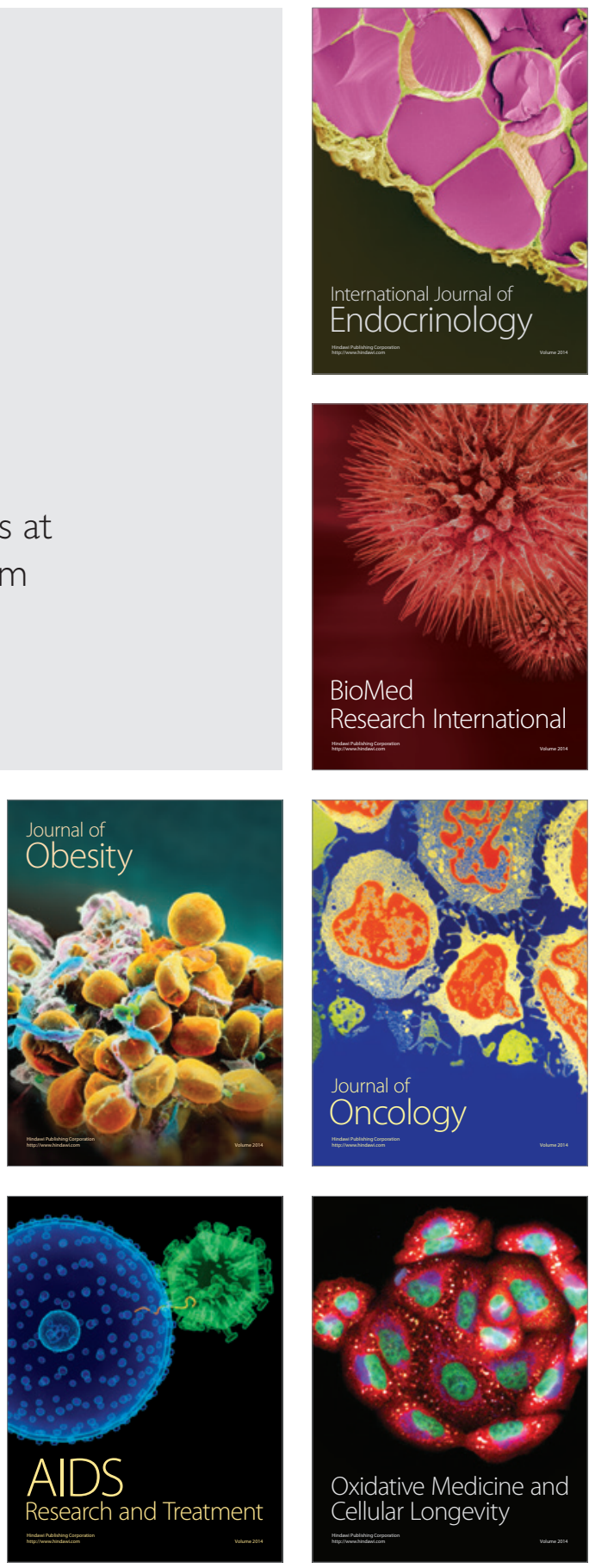